\title{
Los nombres en disputa: Análisis de las estrategias de nominación utilizadas por políticos en medios de comunicación peruanos durante la cobertura de dos casos de corrupción
}

\author{
Disputed names: Analysis of naming strategies used by \\ politicians in Peruvian media during the coverage of two \\ corruption cases
}

\author{
Carolina Arrunátegui \\ Pontificia Universidad Católica del Perú \\ carolina.arrunategui@pucp.pe \\ http://orcid.org/oooo-0oo1-9893-5602
}

\author{
María Mercedes Palomino \\ Universidad San Martín de Porres \\ mpalominog@usmp.pe \\ https://orcid.org/oooo-0oo2-4876-2755
}

\begin{abstract}
Resumen
Este artículo analiza las estrategias de nominación utilizadas por políticos en medios de comunicación peruanos durante la cobertura de dos casos de corrupción en los que estuvo en juego la reputación de dos presidentes de la República. Sobre la base del trabajo de Theodoor van Leeuwen (1996), llamamos estrategias de nominación a las diversas formas en que los políticos nombraron a las personas y a los hechos con la finalidad de controlar significados y construir versiones de acuerdo con sus intereses. Como herramienta de análisis, hemos utilizado el modelo de Representación de Actores Sociales de Van Leeuwen (1996), desde la perspectiva del Análisis Crítico del Discurso, el cual entiende el lenguaje como una práctica social e históricamente situada (Fairclough, 1992 y 2003). Los resultados del análisis muestran que los nombres pueden ser poderosas armas políticas; en este sentido, se debe entender que las prácticas de nominación no son un mero ejercicio de rotulación lingüística, sino prácticas sociales que construyen la realidad, pues nombrar es también crear aquello que se nombra.
\end{abstract}

Palabras clave: Análisis Crítico del Discurso, política, corrupción, medios de comunicación, estrategias de nominación

\begin{abstract}
This article analyzes the naming strategies used by politicians in the Peruvian media during the coverage of two corruption cases in which the reputation of two presidents of the Republic was at stake. Based on the work of Theodoor van Leeuwen (1996), we call naming strategies the various ways in which politicians named people and facts in order to control meanings and build versions according to their interests. As an analytical tool, we have used Van Leeuwen's (1996) model of Representation of Social Actors, from the perspective of Critical Analysis of Discourse, which understands language as a socially and historically situated practice (Fairclough, 1992 and 2003). The results of the analysis show that names can be powerful political weapons; in this sense, it should be understood that naming practices are not merely an exercise in linguistic labeling, but social practices that construct reality, since naming is also creating what is named.
\end{abstract}

Keywords: Critical Discourse Analysis, politics, corruption, media, naming practices 
Los nombres en disputa: Análisis de las estrategias de nominación utilizadas por...

\section{Introducción}

Los medios de comunicación en general y el periodismo político en particular juegan un rol central en la vida de las naciones, pues se espera de ellos que contribuyan a construir una opinión pública informada y capaz de tomar decisiones políticas responsables y orientadas al bien común. Casero-Ripollés (2009) señala dos motivos por los cuales recae sobre ellos esta gran responsabilidad: en primer lugar, porque la información periodística es la fuente primaria de las representaciones simbólicas de la política que llegan a la sociedad, es decir, son los medios de comunicación los que dotan de significado a los acontecimientos políticos y los hacen llegar a la ciudadanía; y, en segundo lugar, porque determinan la prioridad de los eventos socialmente relevantes, es decir, establecen cuál ha de ser la agenda pública.

Por estas razones, todo actor político siempre estará interesado en crear y mantener redes de contactos con los medios; solo de ese modo podrá asegurar su supervivencia en la arena política (Jordi Berrío; citado en Casero-Ripollés, 2008). En ese sentido, debemos entender a los medios de comunicación y a la política como dos sistemas interdependientes: por un lado, el periodista político requiere del político para generar noticia y, por otro lado, el político necesita del espacio mediático para ser visible y alcanzar a la ciudadanía (Casero-Ripollés, 2008; Ortells-Badenes, 2014).

A lo largo del tiempo, los actores políticos han logrado acumular experiencia sobre cómo lograr una mayor presencia en los medios y algún nivel de control sobre la información que es producida y difundida por ellos. Parte crucial de esta experiencia adquirida es el conocimiento sobre las condiciones en las que se producen y se difunden las noticias en el mundo actual. Los políticos más experimentados saben que el quehacer periodístico está condicionado por factores extra periodísticos como la observación de la competencia, el análisis del target o público objetivo, la línea editorial y las limitaciones relacionadas con los recursos técnicos del medio (Ortells-Badenes, 2014). La labor periodística también depende de la estructura institucional de las empresas de comunicación, que funcionan en un contexto en el que imperan la comercialización de los medios, la globalización y la concentración de las empresas de comunicación mediante conglomerados y redes (Castells, 2009).

Así, pues, cada actor político debe encuadrar su discurso tomando en cuenta estos factores, pero además debe conseguir ubicarse en la parte superior de la jerarquización de la noticia para asegurar que su lugar en el noticiero, el tratamiento 
Los nombres en disputa: Análisis de las estrategias de nominación utilizadas por...

Carolina Arrunátegui y María Mercedes Palomino

de su información y la duración de su exposición en el mismo sean los idóneos (Casero-Ripollés, 2009). Y así como hay una preocupación por posicionar una agenda política propia en los informativos, también la hay por controlar que ningún contenido perjudicial sea expuesto o, en el peor de los casos, que su exposición sea la menor en términos de duración (Casero-Ripollés, 2009). De este modo, los medios de comunicación son en realidad un campo de batalla político en el que se disputan los intereses de los grupos con más poder y en el que el lenguaje y su uso juegan un papel central, pues no hay que perder de vista que buena parte de la información y de las representaciones que circulan en los medios lo hacen bajo la forma de discursos hablados, escritos o multimodales.

El objetivo de esta investigación es examinar dos casos de corrupción que fueron muy mediáticos en el Perú y en los que el lenguaje tuvo un rol protagónico. Concretamente, examinamos las estrategias de nominación que fueron utilizadas por políticos peruanos en los medios de comunicación. Sobre la base del trabajo de Theodoor van Leeuwen (1996), llamamos estrategias de nominación a las diversas formas en que estos políticos nombraron o se refirieron a las personas o los hechos con la finalidad de controlar significados y construir realidades de acuerdo con sus intereses a través del discurso. Para examinar estas estrategias, hemos utilizado el modelo de Representación de Actores Sociales (RAs) de Van Leeuwen (1996), que ofrece un inventario sociosemántico de las formas en que los actores sociales pueden ser nombrados y representados en el discurso, y los efectos ideológicos que estas representaciones pueden tener. Volveremos sobre este modelo en el apartado en el que explicamos el marco teórico que utilizamos.

Con respecto a los casos de análisis, abordaremos, en primer lugar, la disputa por el poder entre los expresidentes Ollanta Humala y Alan García, ocurrida en el año 2013, en la que este último resignificó el término «pareja presidencial»y acuñó el término «reelección conyugal» para posicionar a Nadine Heredia, esposa de Ollanta Humala y ex primera dama, como un personaje corrupto que gozaba de un poder político que no le correspondía. A través del uso político de los términos «pareja presidencial»y «reelección conyugal» en los medios de comunicación, el expresidente Alan García dio a entender a la opinión pública que el entonces presidente Ollanta Humala mantenía una situación de cogobierno con su esposa Nadine Heredía, quien, se decía, tenía tanto o más poder que él mismo. Es importante tomar en cuenta que el uso político de estos términos por parte de Alan García se dio en un contexto en el que él estaba siendo investigado por el gobierno de Ollanta Humala por un caso de corrupción. Como segundo caso 
Los nombres en disputa: Análisis de las estrategias de nominación utilizadas por...

de análisis, examinaremos el escándalo de corrupción que precipitó la caída del expresidente Pedro Pablo Kuczynski el año 2018, escándalo en el que los neologismos «mamanivideos», «kenjivideos» $\mathrm{y}$ «keikovideos» fueron utilizados para disputar la responsabilidad de la grabación de una serie de videos que vincularon al expresidente Kuczynski con el delito de tráfico indebido de influencias. En ambos casos de análisis, el lenguaje funcionó como una poderosa arma política que, lejos de representar la realidad de manera objetiva, se convirtió en el lente a través del cual se interpretaron los hechos y se definió, en parte, el destino político de las personas involucradas.

\section{El lenguaje como práctica social}

Esta investigación se desarrolla en el marco del Análisis Crítico del Discurso, un modelo de análisis que entiende el lenguaje como una práctica social e históricamente situada (Fairclough, 1992 y 2003). El Análisis Crítico del Discurso enfatiza la relación dialéctica que existe entre el lenguaje y lo social, por lo que su objetivo principal es explorar las relaciones entre las prácticas discursivas y los acontecimientos sociohistóricos que las circundan (Achugar, 1999).

En tanto práctica social, el lenguaje no se limita a representar la realidad de manera transparente $\mathrm{o}$ a nombrar significados que ya existen en el mundo, fuera del lenguaje (Hall, 2010). Más bien, el uso del lenguaje se concibe como un acto performativo a través del cual quien habla o escribe está a la vez construyendo identidades, relaciones sociales y versiones del mundo, siempre desde un punto de vista particular (Fairclough, 1992 y 2003). En este sentido, resulta útil entender los textos como productos culturales cargados de los significados históricos y sociales de los grupos en los que son producidos, y también como el resultado de un proceso continuo de selección semántica. Cada palabra dicha o escrita implica haber dejado de lado otras múltiples opciones y, con ellas, otras posibilidades de significación. Como señala Michael Halliday en su propuesta de un modelo sistémico funcional de la gramática, más que un set de reglas (lo que debe ser dicho), la gramática debe ser entendida como un «potencial de significado» (lo que puede ser dicho) (Halliday, citado en Van Leeuwen, 1996). Así, pues, los discursos de los políticos que analizamos en esta investigación deben verse de este modo, es decir, no como representaciones objetivas de la realidad, sino como el resultado de una selección consciente y orientada de términos y estructuras discursivas

318 Lengua y Sociedad. Revista de Lingüística Teórica y Aplicada 
Los nombres en disputa: Análisis de las estrategias de nominación utilizadas por... Carolina Arrunátegui y María Mercedes Palomino

que construyen los hechos y las identidades de las personas de manera funcional a intereses personales o de grupo.

Nuestro análisis es una aplicación del modelo de Representación de Actores Sociales (RAS) de Van Leeuwen (1996) al Análisis Crítico del Discurso. Consideramos que este modelo aporta las herramientas necesarias para explorar las múltiples posibilidades de significación del discurso, en especial de los nombres, en contextos sociales específicos. El modelo RAs parte de la idea de que ninguna forma de nombrar es neutral y se plantea las siguientes preguntas: ¿de qué maneras los actores sociales pueden ser nombrados y representados en el discurso?, ¿qué opciones nos ofrece el lenguaje para referirnos a las personas? Como respuesta, Van Leeuwen (1996) propone un inventario sociosemántico de las distintas maneras en las que la gente puede ser clasificada en el mundo social. Es «sociosemántico» porque pone el énfasis en el análisis social y no en el análisis lingüístico. El objetivo último de este modelo es poder explicar los efectos ideológicos de las distintas formas de nombrar a los actores sociales y cómo, a través de ellas, se puede disputar la construcción de distintos tipos de identidad y de agencia social (Van Leeuwen, citado en Machin y Mayr, 2012).

Así, por ejemplo, no es lo mismo decir «Keiko Fujimori se negó a declarar ante la prensa», que «Lideresa del partido Fuerza Popular se negó a declarar ante la prensa» o «Hija del reo Alberto Fujimori se negó a declarar ante la prensa». En los tres casos, el lenguaje está haciendo referencia a la misma persona (Keiko Fujimori), pero es evidente que cada una de esas tres maneras de nombrarla representa su identidad y su agencia social de formas radicalmente distintas porque activan significados, metáforas e imágenes también diferentes. En este punto, es importante tomar en cuenta que la noción de agencia del modelo RAs no es la misma que la agencia gramatical o lingüística. La agencia social que utiliza Van Leeuwen (1996) está referida a la capacidad que tiene un sujeto social para actuar sobre el mundo con voluntad y control. En este sentido, no pueden ser agentes entidades inanimadas o abstractas. Lo importante, entonces, es identificar quién(es) hace(n) qué y con qué efectos. Así, pues, en esta investigación, entendemos el nombrar como una práctica social en la que se disputan identidades, poder y agencia social.

\section{Metodología}

Esta investigación tiene un carácter cualitativo y se desarrolló en tres etapas. En la primera etapa, identificamos dos casos de corrupción política relativamente 
Los nombres en disputa: Análisis de las estrategias de nominación utilizadas por... Carolina Arrunátegui y María Mercedes Palomino

recientes y de impacto mediático en el Perú: en primer lugar, la acusación de usurpación de poder que hizo el expresidente Alan García en el año 2013 contra la entonces primera dama Nadine Heredia y, en segundo lugar, la caída del expresidente Pedro Pablo Kuczynski a inicios del 2018 a raíz de unos videos que lo vincularon al tráfico de influencias. Ambos casos resultaron interesantes para nosotras porque en ellos era evidente que el lenguaje estaba jugando un rol decisivo. Los actores políticos involucrados en estos casos se esforzaron por crear o resignificar diversos nombres con la finalidad de proteger su propia imagen pública y perjudicar la de sus contendores. Eran situaciones en las que se podía ver con claridad cómo los medios de comunicación se convirtieron en un campo de batalla político-discursivo. En el primer caso de análisis, los términos que sobresalieron fueron «pareja presidencial» $\mathrm{y}$ «reelección conyugal», mientras que en el segundo caso identificamos los términos «mamanivideos», «kenjivideos» $\mathrm{y}$ «keikovideos».

Una vez identificados los casos y los términos que nos interesaban, procedimos a realizar un análisis de contenido exploratorio (Gaitán y Piñuel, 1998; Bardin, 2002) sobre un conjunto de noticias que abordaron los casos en cuestión en los diarios digitales más leídos en el Perú. El objetivo de esta segunda etapa fue identificar los contextos lingüísticos de aparición de los términos. Los medios de comunicación consultados fueron los siguientes: larepublica.pe, elcomercio.pe, peru21.pe, rpp.pe, diariocorreo.pe, y americatv.com.pe. Estos son los seis medios digitales peruanos más leídos, según el reporte de sitios top por país desarrollado por SimilarWeb en el año 2019. Se realizó una revisión de las plataformas digitales de estos diarios a partir de la herramienta de búsqueda avanzada de Google, a través de la cual se seleccionaron las opciones referidas exclusivamente a titulares y página de ubicación.

Decidimos trabajar solo con titulares y no con noticias completas, porque en la actual era del 'clicbait', los titulares se han convertido en la principal herramienta de venta de los millones de noticias que circulan en la red. En las ediciones online, los titulares tienen la cualidad de poder construirse y modificarse según el interés que vayan suscitando y durante el tiempo de vida de la noticia. Pero, más importante todavía, suelen ser con frecuencia la referencia informativa con la que se quedan los lectores (Costa-Sánchez, 2011). Es decir, los titulares pueden servir para incitar al lector a leer la información, pero también para darla por leída y pasar a otra noticia (Gomis, citado en López-Hidalgo, 2009, p. 18). Además de titulares,

1 SimilarWeb es una de las herramientas de marketing digital más utilizadas en la actualidad. Permite conocer con exactitud las principales estadísticas y el desempeño de una página web. 
Los nombres en disputa: Análisis de las estrategias de nominación utilizadas por...

Carolina Arrunátegui y María Mercedes Palomino

trabajamos con las etiquetas de cada página de noticias, también conocidas como tags. Los tags son palabras clave que definen la búsqueda de información de los usuarios y son ahora uno de los hipervínculos semánticos de mayor uso en los medios de comunicación digitales. Para llevar a cabo la búsqueda de tags, hicimos una revisión a partir de los motores de búsqueda de las propias páginas de noticias y los enlaces referidos a tags en la propia morfología de sus direcciones o links.

Los resultados de la búsqueda mostraron que los nombres que analizamos en esta investigación tuvieron una presencia notable en los medios digitales mientras duró la cobertura de los casos. «Pareja presidencial» apareció en 202 titulares y 198 publicaciones con el mismo tag, en tanto que «reelección conyugal» sumó 67 apariciones en titulares y 390 apariciones en tags. En el caso de «mamanivideos», «kenjivideos» y "keikovideos», estos términos sumaron 132, 100 y 69 en titulares respectivamente, en tanto que su aparición en tags fue de 181, 177 y 72, respectivamente. En todos los casos, se procedió a identificar los significados que iban adquiriendo los términos en sus contextos lingüísticos, pero también en relación con sus contextos sociopolíticos. Esto último constituyó la tercera y última etapa del trabajo de análisis, que se hizo desde la perspectiva del Análisis Crítico del Discurso (Fairclough, 1992 y 2003), utilizando las herramientas que aporta el modelo de Representación de Actores Sociales de Van Leeuwen (1996).

\section{Análisis}

\subsection{Dos presidentes, un sillón presidencial}

«Pareja presidencial»y «reelección conyugal» son términos que se volvieron muy populares el año 2013 a raíz de que fueron pública y continuamente utilizados por Alan García, exlíder del partido aprista y presidente del Perú en dos ocasiones (en los periodos 1985-1990 y 2006-2011), durante su disputa política con el entonces presidente Ollanta Humala, líder del Partido Nacionalista Peruano. En ese entonces, García estaba siendo investigado por el gobierno de Humala por haber concedido alrededor de 400 indultos a sentenciados por tráfico ilícito de drogas durante su segundo mandato. El caso llegó a ser popularmente conocido como el caso «narcoindultos» (La República, 2019).

Ante las acusaciones por parte del gobierno, García declaró en sus redes sociales y en la prensa que estas no eran más que un ataque de Humala para dejarlo fuera de una futura candidatura presidencial y posicionar en su lugar a su esposa y 
Los nombres en disputa: Análisis de las estrategias de nominación utilizadas por...

entonces primera dama de la República, Nadine Heredia. Durante el mandato de Humala, corrió fuertemente el rumor de que Nadine Heredia tenía tanto poder político como el propio presidente y que albergaba planes de ser candidata presidencial para el periodo 2016-2021. El rumor se fortaleció todavía más a raíz de las declaraciones de Rosa Mávila, entonces congresista oficialista, quien en marzo del 2012 dejó entrever que Nadine Heredia cogobernaba con el presidente Ollanta Humala (Ortiz, 2012).

En este contexto, Alan García utilizó por primera vez «pareja presidencial» para referirse a Nadine Heredia y a Ollanta Humala, y su supuesto poder político compartido (Tafur, 2012). Un primer aspecto interesante del uso político que se hizo de este término es que, en el contexto de esta disputa, "pareja presidencial» atravesó por un proceso de «relexicalización» (Fowler y otros, 1979/2018). Es decir, si bien este término es utilizado en muchos otros contextos para referirse a un presidente y la primera dama, en este caso en concreto, "pareja presidencial» se resignificó y empezó a hacer referencia a Ollanta Humala y Nadine Heredia de manera exclusiva y bajo la connotación de cogobierno, es decir, vinculando valoraciones negativas como «corrupción» $\mathrm{y}$ «colusión». El término resignificado fue bien acogido por los medios. Como señalamos líneas arriba, «pareja presidencial» apareció en 202 titulares y 198 publicaciones con el mismo tag en los medios más leídos del país durante el periodo 2013, y con el significado particular que le había dado Alan García. Si bien a partir de nuestros datos no podemos afirmar con plena seguridad que los medios tomaron partido por el término resignificado y la interpretación que este proponía, sí es verdad que lo utilizaron activamente en titulares y le dieron mucha visibilidad.

Ahora bien, «pareja presidencial» es también lo que el lingüista Theodoor van Leeuwen (1996) llama una asociación, esto es, un término que une dos o más personas o grupos de personas, de modo que sus diferencias quedan relegadas y se enfatiza la idea de alianza o causa común. Se asume que los sujetos asociados están involucrados en algún tipo de actividad conjunta. El nombre «pareja presidencial» aporta una poderosa metáfora que nos permite visualizar a Ollanta Humala y Nadine Heredia sentados juntos en el sillón presidencial, compartiendo el poder y dirigiendo desde ahí el destino del país. En el marco de esta imagen, es posible borrar del discurso (y de la realidad) las diferencias en el pensar y actuar que pudieran existir entre Ollanta Humala y Nadine Heredia e imaginarlos fusionados en una unidad más o menos estable. A partir del uso estratégico de este nombre, García logró reorientar el ojo público hacia el gobierno de Humala 
Los nombres en disputa: Análisis de las estrategias de nominación utilizadas por...

Carolina Arrunátegui y María Mercedes Palomino

para ser juzgado y colocar en segundo plano las acusaciones que pesaban sobre sí mismo por el caso «narcoindultos».

Además de «pareja presidencial», Alan García utilizó de manera reiterada en los medios el término «reelección conyugal» para señalar los supuestos planes de Nadine Heredia de ser candidata en las elecciones presidenciales del 2016 y asegurar así la continuidad en el poder del partido nacionalista liderado por su esposo. De ahí el uso del término «reelección». En este caso, es importante notar la inserción de una evaluación (Van Leeuwen, 1996) a través del adjetivo «conyugal». Al calificar de «conyugal» un proceso electoral, García está evaluando los hechos desde su propio interés y construyendo discursivamente la realidad, de modo que hace converger la política con las relaciones personales, es decir, lo público con lo privado, que son espacios que en el imaginario común deben estar estrictamente separados. Así, las ideas de «corrupción», «colusión» e incluso «nepotismo» emergen y refuerzan el estigma y la sanción social en contra de Ollanta Humala y Nadine Heredia.

Al igual que "pareja presidencial», el término «reelección conyugal» circuló con frecuencia en los medios. Sumó 67 apariciones en titulares y 390 apariciones en tags en el año 2013. El 18 de mayo de 2013, en una entrevista al diario Perú 21, García aseguró que él representaba una «amenaza para la "reelección conyugal"» (Perú 21, 2013) y que por eso era injustamente hostigado por el gobierno de Humala, lo mismo que otros posibles adversarios políticos como el expresidente Alejandro Toledo, quien en ese momento también estaba siendo investigado por unas cuestionadas adquisiciones inmobiliarias a través de su suegra. En esa misma entrevista, para asegurar un mayor impacto de sus intervenciones, García señaló la supuesta candidatura presidencial de Nadine Heredia como una amenaza "chavista», haciendo referencia al expresidente venezolano Hugo Chávez: «Las maniobras chavistas que están utilizando con mucha torpeza son propias de quienes quieren mantenerse en el poder» (Perú 21, 2013). En los días siguientes, en abril del 2013, aparecieron pintas firmadas por el grupo aprista Renov@r con la frase «No a la reelección conyugal» en los distritos del Rímac y San Martín de Porres (América Noticias, 2013). Estas pintas fueron una reacción a las declaraciones de García en las que utilizó por primera vez el término «reelección conyugal». El acto fue recogido por los medios señalando como autor de la frase al ex presidente aprista. Los integrantes de esta agrupación señalaron que realizaron las pintas por preocupación ante una posible candidatura de Nadine Heredia e indicios de chavismo en el Gobierno. 
Los nombres en disputa: Análisis de las estrategias de nominación utilizadas por...

Asimismo, durante abril de 2013, se reprodujo en los medios un meme que se había viralizado en redes sociales con el título «Cédula para la Reelección Conyugal-Perú 2016» (Perú.com, 2013). La imagen era una cédula de sufragio con el rostro de Nadine Heredia repetido en más de una decena de casilleros, haciendo alusión a la cédula de votación venezolana en la que aparecía de igual forma Nicolás Maduro. A través de su página de Facebook, García dejó mensajes atribuyéndose el trabajo de frenar dicha «amenaza»: "Garantizo que no van a poder hacer la reelección conyugal», publicó el 7 de abril de 2013. Un año después, el 19 de junio de 2014, escribió: «Los informes nulos de Tejada [sobre el caso "narcoindultos"] son una patraña mayor que el informe Lark de 1991. Me odian por haber impedido la reelección conyugal».

Los casos de "pareja presidencial»y «reelección conyugal» nos muestran con claridad que los significados no están fijos ni se encuentran en las palabras en sí mismas, sino que son flexibles y se negocian entre los hablantes en el marco de una situación concreta. El significado está siempre en permanente construcción y depende de las relaciones sociales y de poder que están en juego. En la construcción del significado importa mucho entonces quién lo dice, a quién se lo dice, en qué situación y qué intereses hay de por medio (Gee, 2001). Así, pues, que los términos «pareja presidencial»y «reelección conyugal» se hayan convertido en armas políticas muy efectivas en contra de Ollanta Humala y Nadine Heredia es el resultado del trabajo del poder, esto es, del poder de un personaje político como Alan García, que contó en su momento con los recursos materiales y simbólicos para llegar a los medios e introducir su propia perspectiva en el discurso público. Pensemos que si estos términos (con estos significados específicos) hubieran sido utilizados por un sujeto sin poder y sin acceso a los medios, difícilmente hubieran logrado posicionarse en la esfera pública. Aquí no está demás aclarar que, como investigadoras, nosotras no estamos tomando partido por Ollanta Humala y Nadine Heredia. No conocemos y tampoco es nuestro objetivo conocer «la verdad» detrás de las acusaciones de usurpación de poder contra Nadine Heredia. Nuestro objetivo al abordar este caso es más bien analizar el uso político que se está haciendo del lenguaje, y los efectos ideológicos y materiales que este uso pueda tener. Más que develar «la verdad» de los hechos, estamos interesadas en observar el poder del lenguaje para construir la realidad y mediar nuestra relación con ella.

324 Lengua y Sociedad. Revista de Lingüística Teórica y Aplicada 
Los nombres en disputa: Análisis de las estrategias de nominación utilizadas por...

Carolina Arrunátegui y María Mercedes Palomino

\subsection{Los «mamanivideos" y la caída del expresidente Pedro Pablo Kuczynski}

En el año 2018, el Partido Fuerza Popular, liderado por Keiko Fujimori, dio a conocer una serie de videos grabados por el excongresista de su bancada Moisés Mamani, que sacaron a la luz los vínculos de corrupción que existían entre Kenji Fujimori, excongresista y líder del bloque disidente fujimorista del Partido Fuerza Popular, y el entonces presidente de la República Pedro Pablo Kuczynski. En los videos más importantes, puede observarse a Kenji Fujimori y otros parlamentarios de su bloque sobornando a Moisés Mamani a cambio de votar en contra del segundo pedido de vacancia presidencial contra Pedro Pablo Kuczynski, quien desde el año 2017 venía siendo acusado de incapacidad moral. Estos hechos desencadenaron la renuncia de Kuczynski a la Presidencia de la República el 21 de marzo de 2018, y la suspensión de Kenji Fujimori y su grupo por los delitos de cohecho y tráfico de influencias.

Durante todo este proceso que culminó con la caída del gobierno de Kuczynski, se dio lugar una batalla en el terreno del lenguaje en la que se disputó cuál iba a ser el nombre que debían recibir los videos en cuestión. Esta dimensión lingüística del conflicto resultó crucial porque determinó quiénes eran las víctimas y quiénes los culpables, y, por lo tanto, decidió en parte el futuro político de los involucrados en este caso de corrupción. Estas disputas por los nombres nos muestran, tal como afirma Van Leeuwen (1996), que las prácticas de nominación tienen una dimensión política importante porque, en contextos específicos, pueden asignar responsabilidades, es decir, expresar quién hace qué y con qué efectos.

Así, pues, desde distintos frentes, los actores políticos acunaron términos y construyeron significados de acuerdo a sus intereses. La estrategia que utilizaron fue la composición (Varela, 1990), que consistió en unir dos sustantivos o nombres para formar neologismos. Como resultado de este proceso morfológico surgieron los términos «mamanivideos», «kenjivideos» y «keikovideos». En estos neologismos, el nombre común «video» aparece unido al nombre propio de la persona a quien se quería responsabilizar por estas grabaciones: «Mamani» (el excongresista Moisés Mamani del Partido Fuerza Popular, a quien se acusaba de ser el autor material de los videos grabados de manera ilícita), «Kenji» (Kenji Fujimori, entonces líder del bloque disidente fujimorista del Partido Fuerza Popular, a quien los videos muestran sobornando al congresista Mamani) y «Keiko» (Keiko Fujimori, lideresa del Partido Fuerza Popular, acusada de ser quien ordenó al 
Los nombres en disputa: Análisis de las estrategias de nominación utilizadas por...

congresista Mamani la grabación ilícita de los videos con la finalidad de poner una «trampa» a Kenji Fujimori).

Esta estrategia de nominación tiene un antecedente importante en el Perú que carga con un enorme estigma. Poco más de veinte años atrás, en el 2000, se hizo muy popular el término "vladivideo», el cual se utilizó para nombrar una serie de videos en los que Vladimiro Montesinos, el entonces asesor presidencial del expresidente Alberto Fujimori, filmaba a los funcionarios que corrompía. El escándalo de corrupción que protagonizaron Alberto Fujimori y Vladimiro Montesinos ha sido calificado como el más grande de la historia del Perú, pues involucró a importantes políticos, empresarios, miembros de las Fuerzas Armadas, del Poder Judicial y de los medios de comunicación; contó incluso con el apoyo del narcotráfico. Es decir, la corrupción de este gobierno, que duró 10 años (1990-2000), logró penetrar casi todos los sectores del país. El historiador Alfonso Quiroz (2014) describe así el lugar que ocupan Fujimori y Montesinos en la historia de la corrupción peruana: «En la historia del Perú ha habido varios ejemplos clásicos de entendimiento dual en la cúpula de gobiernos signados por el abuso del poder: el virrey Amat-asesor Salas, Gamarra-Gutiérrez de La Fuente, Echenique-Torrico, Balta-Piérola, Piérola-Dreyfus, Leguía-Ego-Aguirre, OdríaNoriega, Velasco-Tantaleán y García-Mantilla, entre otros. Sin embargo, el dúo Fujimori-Montesinos probablemente superó a todos ellos en términos del alcance y profundidad de la corrupción» (p. 399). Los términos «mamanivideos», «kenjivideos» $\mathrm{y}$ «keikovideos» heredaron buena parte del estigma que pesa sobre los «vladivideos»y, por ello, resultan más que comprensibles los grandes esfuerzos que hicieron los políticos involucrados en el caso por no ver sus nombres como parte de tan infame creación lingüística, especialmente Kenji y Keiko Fujimori, que estaban prácticamente repitiendo la historia de corrupción de su padre, Alberto Fujimori.

De estos tres nombres, el primero que apareció en los medios fue el de «kenjivideos». Lo hizo circular el partido de Keiko Fujimori, Fuerza Popular, con la finalidad de señalar a Kenji Fujimori como responsable de soborno y colusión con el entonces presidente Pedro Pablo Kuczynski. Así, pues, con el uso de este término no solo estaba en juego la reputación de Kenji Fujimori sino también la de Kuczynski. Kenji Fujimori había renunciado al partido de su hermana Keiko a inicios del 2018 y había formado un bloque disidente con un grupo de congresistas que lo acompañaron en su renuncia. La separación se dio por una marcada divergencia de objetivos políticos: mientras que el principal objetivo de Kenji Fujimori 
Los nombres en disputa: Análisis de las estrategias de nominación utilizadas por...

Carolina Arrunátegui y María Mercedes Palomino

fue la liberación de su padre Alberto Fujimori, condenado a 25 años de prisión, el objetivo de Keiko Fujimori fue dominar los poderes del Estado, a través de una mayoría congresal, y desestabilizar la gobernabilidad del presidente Kuczynski. Es en este contexto que se hicieron públicos los videos.

Como respuesta a los «kenjivideos», Kenji Fujimori y su grupo disidente acuñaron el término «keikovideos», que buscó resaltar que las grabaciones se habían hecho subrepticiamente bajo las órdenes de Keiko Fujimori y que se había violado su derecho a la intimidad. En una entrevista concedida a ATV Noticias del 20 de marzo de 2018, Kenji Fujimori se refirió a los videos como una campaña montada por su hermana Keiko «para recuperar a cualquier costo la mayoría absoluta del Congreso» (ATV Noticias, 2018). Aseguró también que la grabación de los videos «no se trata[ba] de una lucha contra la corrupción, sino de una lucha por el poder» (ATV Noticias, 2018). De este modo, Kenji Fujimori intentó colocar fuera del foco de atención sus propios actos de corrupción revelados en las grabaciones.

Sin embargo, poco después, empezó a cobrar fuerza en los medios un tercer nombre, los «mamanivideos». Con este término, la responsabilidad de los videos fue adjudicada al congresista de Fuerza Popular Moisés Mamani, quien era, en efecto, el autor material de las grabaciones que actuó bajo las órdenes de Keiko Fujimori. Pero, a diferencia de los otros dos términos, los «mamanivideos» lograron librarse del estigma de los «vladivideos» y no trajeron consigo valoraciones negativas para su protagonista Mamani, sino que construyeron la grabación ilícita de los videos como un acto de justicia necesario para develar la colusión entre Kenji Fujimori y Pedro Pablo Kuczynski. Por esa razón, el término «mamanivideos» apareció con frecuencia acompañado por el neologismo «Súpermamani» (Lima al Día, 2018), que representó a Mamani como un héroe, como el autor de una hazaña y no de un delito.

Esta batalla política y discursiva la ganó finalmente el grupo de Keiko Fujimori porque todo culminó con la derrota política de Pedro Pablo Kuczynski y Kenji Fujimori, el primero renunciando a la presidencia y el segundo separado del Congreso y acusado de cohecho y tráfico de influencias. Fue finalmente el término «mamanivideos» el que mejor se posicionó en los medios y el que marcó la pauta para la interpretación de los hechos. En efecto, nuestra revisión de noticias a partir del motor de búsqueda de Google muestra que el término «mamanivideos» aparece en 132 titulares y 181 tags, «kenjivideos» en 100 titulares y 177 tags, y «keikovideos» solo en 69 titulares y 72 tags. A partir de estos datos constatamos que, en general, la versión que tuvo más visibilidad fue la de entender la grabación de los 
Los nombres en disputa: Análisis de las estrategias de nominación utilizadas por... Carolina Arrunátegui y María Mercedes Palomino

videos como un hecho necesario para sacar a la luz un caso de corrupción que involucró al entonces presidente Kuczynski. Poco importó entonces la naturaleza ilícita de las grabaciones - hay que recordar aquí que el excongresista Mamani actuó como señuelo y grabó las conversaciones que sostuvo con Kenji Fujimori utilizando un lapicero con cámara oculta-, lo que nos muestra que lo importante no son los hechos en sí mismos, sino la representación que de ellos prevalece; el lenguaje no «refleja» el mundo de manera transparente, sino que su uso implica siempre un proceso activo de construcción de la realidad.

\section{Conclusiones}

El análisis de los dos casos que hemos abordado en esta investigación nos ha mostrado que los nombres pueden ser poderosas armas políticas en el contexto de una disputa mediática, que pueden tener importantes consecuencias materiales como la apertura de un proceso de investigación o el colapso de un gobierno. En este sentido, debemos entender que las prácticas de nominación no son un mero ejercicio de rotulación lingüística de los hechos y las personas, sino prácticas sociales que implican la construcción activa del significado de los hechos y de las identidades de las personas. Nombrar es también crear aquello que se nombra. Esto es parte del poder constitutivo del lenguaje y de su capacidad de mediar la forma en la que nos relacionamos con la realidad (Fairclough, 1992 y 2003).

Así, por ejemplo, hemos podido observar el modo en que nombres como «pareja presidencial» $\mathrm{o}$ «reelección conyugal» se utilizaron políticamente para interpretar y darle forma al vínculo y al quehacer político del expresidente Ollanta Humala y la ex primera dama Nadine Heredia. Estos nombres aportaron una poderosa metáfora según la cual Humala y Heredia estaban sentados juntos, compartiendo el sillón presidencial. A partir de esta metáfora, Alan García logró dañar la reputación del gobierno de Humala y restarle legitimidad y visibilidad a la investigación que recaía sobre sí mismo por el caso «narcoindultos». Del mismo modo, parte importante del enfrentamiento político entre Keiko Fujimori, Kenji Fujimori y Pedro Pablo Kuczynski se desarrolló en el terreno del lenguaje, a través de la lucha por darle un nombre a los videos que involucraron al entonces presidente Kuczynski en actos de corrupción. Con estos nombres (los «mamanivideos», los «kenjivideos» y los «keikovideos»), los políticos se estaban jugando su imagen pública y su responsabilidad en un caso de corrupción que finalmente trajo abajo el gobierno de Pedro Pablo Kuczynski. 
Los nombres en disputa: Análisis de las estrategias de nominación utilizadas por... Carolina Arrunátegui y María Mercedes Palomino

Ahora bien, los medios de comunicación suelen ser uno de los escenarios más importantes en los que se desarrollan estas batallas discursivo-políticas. Los casos analizados nos han mostrado cómo los políticos han sabido utilizar los medios y las redes sociales para posicionar sus contenidos y sus puntos de vista ante el ojo público. Sin embargo, es importante aclarar que somos conscientes de que el rol político de los medios no es pasivo; no creemos que funcionen solo como un contenedor o una vitrina de exposición de los discursos de los políticos. Los medios son también actores políticos que toman decisiones con respecto a la información que difunden. Como señalamos en la introducción de esta investigación, los medios son la principal fuente de representaciones simbólicas sobre la política que tiene la ciudadanía y marcan la pauta respecto de cuáles son los temas de interés público. Los medios no difunden los discursos políticos tal como son producidos en sus contextos originales, sino que los intervienen de diversas maneras. Dentro de ciertos límites, los medios deciden qué información difundir y qué no, qué enfoque va a recibir la noticia o por cuánto tiempo va a circular y de qué modos. De hecho, existen numerosas investigaciones hechas en el contexto político peruano que examinan con detalle el discurso de los medios y las estrategias discursivas que utilizan para construir el significado y la interpretación de la noticia (Arrunátegui, 2010a y 2010b; Flores, 2012; Torrejón, 2013; Espinoza, 2016; entre otros). Así, pues, la información política que llega a la sociedad a través de los medios es el producto de una red compleja de relaciones de poder entre los medios, la clase política y otras esferas del poder. Las victorias o las derrotas políticas no solo las construyen los políticos sino también los medios.

Por esta razón, creemos que es fundamental desarrollar una mirada crítica respecto del uso del lenguaje que hacen los políticos y los medios, lo cual implica no solo tomar consciencia sobre sus discursos, sino también sobre los procesos de producción, distribución y consumo que enmarcan estos discursos. Tal como propone el Análisis Crítico del Discurso, los discursos no se generan en el vacío, sino que están siempre atados a los contextos sociohistóricos y las relaciones de poder que los circundan. Por ello, Fairclough (1992 y 2003) propone entender los textos como fenómenos tridimensionales, es decir, no solo como redes de estructuras lingüísticas, sino también como prácticas discursivas y como prácticas sociales. Asimismo, creemos igualmente importante observar críticamente los discursos producidos por la ciudadanía porque estos reproducen o recrean los discursos mediáticos-políticos. En este sentido, son necesarios estudios que 
Los nombres en disputa: Análisis de las estrategias de nominación utilizadas por...

aborden la recepción de los discursos del poder y cómo estos son intervenidos y resignificados por la ciudadanía.

Esta mirada crítica integral, enfocada en todos los actores sociales que son relevantes en los procesos políticos, se hace todavía más urgente si tomamos en cuenta que hemos llegado al Bicentenario de la Independencia del Perú arrastrando los problemas y las taras que ya estaban presentes desde nuestro nacimiento como república. Son doscientos años de corrupción republicana, al parecer ininterrumpida, tal como consta en el trabajo del historiador Alfonso Quiroz (2014), quien se dio a la enorme tarea de historizar los orígenes de la corrupción peruana desde los tiempos de la Colonia y su evolución hasta la década del 2000, durante el gobierno de Alberto Fujimori. Los veinte años posteriores al trabajo de Quiroz (2014) nos ofrecen un panorama deplorable: casi todos los presidentes peruanos elegidos entre los años 2000 y 2016 están encarcelados o enfrentando acusaciones por delitos de corrupción, lo cual nos demuestra que los cimientos de nuestra república continúan profundamente socavados y que los ciudadanos peruanos seguimos encontrando serios obstáculos para ejercer nuestros derechos y deberes plenamente.

330 Lengua y Sociedad. Revista de Lingüística Teórica y Aplicada 
Los nombres en disputa: Análisis de las estrategias de nominación utilizadas por... Carolina Arrunátegui y María Mercedes Palomino

\section{Referencias bibliográficas}

Achugar, M. (1999). Construcción de la memoria: análisis de la confesión de un represor. Discurso y Sociedad, 1(4), pp.7-33.

América Noticias. (2013). Aparecen enormes pintas contra Nadine con frase de García: «No a la reelección conyugal». https://www.americatv.com.pe/noticias/actualidad/aparecen-enormes-pintas-contra-nadine-con-frase-de-garcia-no-la-reeleccion-conyugal-n107210

Arrunátegui, C. (2010a). El racismo en la prensa escrita peruana. Un estudio de la representación del Otro amazónico desde el Análisis Crítico del Discurso. Discurso \& Sociedad, 4(3), 428-470.

Arrunátegui, C. (2010b). Ideología y prensa escrita en el Perú: el caso Bagua. Lexis, 34(2), 353-368.

ATv Noticias. (2018). Kenji Fujimori asegura que los videos fueron editados [Video]. Youtube. https://www.youtube.com/watch?v=R3ZcI4oHtEk

Bardin, L. (2002). Análisis de contenido. Akal.

Casero-Ripollés, A. (2008). Modelos de relación entre periodistas y políticos: La perspectiva de la negociación constante. Estudios sobre el Mensaje Periodístico, $14,111-128$.

Casero-Ripollés, A. (2009). El control político de la información periodística. Revista Latina de Comunicación Social, 64, 354-366.

Castells, M. (2009). Comunicación y Poder. Alianza.

Costa-Sánchez, C. (2011). Tratamiento informativo de una crisis de salud pública: Los titulares sobre gripe A en la prensa española. Revista de la SEECI, 14(25), 43-62.

Espinoza, E. G. (2016). Las representaciones del "Caso Conga» en la prensa escrita peruana: análisis crítico e interpretación de los discursos periodísticos de portada de los diarios El Comercio y La República durante los primeros meses del conflicto socioambiental en torno al proyecto minero Conga [Tesis de licenciatura, Pontificia Universidad Católica del Perú]. Repositorio Institucional PUCP. http://hdl.handle.net/20.500.12404/7385

Fairclough, N. (1992). Discourse and social Change. Cambridge Polity.

Fairclough, N. (2003). Analysing Discourse: Textual Analysis for Social Research. Routledge.

Flores, G. C. (2012). Actores y procesos sociales en La Oroya (1999-2009): un análisis de los discursos de la empresa Doe Run Perú, de sus trabajadores y de dos medios 
Los nombres en disputa: Análisis de las estrategias de nominación utilizadas por...

de comunicación escrita [Tesis de maestría, Pontificia Universidad Católica del Perú]. Repositorio Institucional PUCP. http://hdl.handle.net/20.500.12404/1568

Fowler, R., Hodge, B., Kress, G. y Trew, T. (2018). Language and control. Routledge. (Obra original publicada en 1979)

Gaitán, J. y Piñuel, J. (1998). Técnicas de investigación en comunicación social. Síntesis.

Gee, J. (2001). Reading as situated language: A sociocognitive perspective. Journal of adolescent \& adult Literacy, 44(8), 714-725.

Hall, S. (2010). El trabajo de la representación. En E. Restrepo, C. Walsh y V. Vich (Eds.), Sin garantías (pp. 445-480). Instituto de Estudios Peruanos.

La República. (2019). Narcoindultos: Sergio Tejada indica que evaluará pedir a la fiscalía que reabra caso. La República. https://larepublica.pe/politica/2019/12/10/narcoindultos-sergio-tejada-indica-que-evaluara-pedir-a-fiscalia-que-reabra-caso-jorge-del-castillo-apra

Leeuwen, T. van (1996). The representation of social actors. En C. R. CaldasCoulthard y M. Coulthard (Eds.), Texts and practices. Readings in Critical Discourse Analysis (pp. 32-70). Routledge.

Lima al Día. (2018). «Súper» Mamani Colquehuanca terminó tumbando al presidente Kuczynski Godard. https://limaaldia.pe/2018/o3/22/super-mamani-colquehuanca-termino-tumbando-al-presidente-kuczynski-godard/

López-Hidalgo, A. (2009). El titular. Manual de titulación periodística. Alfaomega. Machin, D. y Mayr, A. (2012). How to do critical discourse analysis. Sage.

Ortells-Badenes, S. (2014). Los criterios de noticiabilidad periodística en los programas de infoentretenimiento. Texto y Visual Media, 64, 341-353. http:// textualvisualmedia.com/index.php/txtvmedia/article/view/90/73

Ortiz, S. (2012). «Humala miente sobre papel de Nadine Heredia en el Gobierno», sostuvo Rospigliosi. El Comercio. https://archivo.elcomercio.pe/amp/politica/ gobierno/humala-miente-sobre-papel-nadine-heredia-gobierno-sostuvo-rospigliosi-noticia-1392950

Perú.com. (2013). Memes: Nadine Heredia aparece hasta 16 veces en la cédula de «reelección conyugal». Perú.com. https://peru.com/actualidad/otras-noticias/nadine-heredia-crean-meme-donde-ella-aparece-16-veces-cedula-reeleccion-conyugal-noticia-132243

Perú21. (2013). Alan García: «Soy una amenaza para la reelección conyugal». Perú 21. https://peru21.pe/politica/alan-garcia-amenaza-reeleccion-conyugal107134-noticia/ 
Los nombres en disputa: Análisis de las estrategias de nominación utilizadas por... Carolina Arrunátegui y María Mercedes Palomino

Quiroz, A. (2014). Historia de la corrupción en el Perú. Instituto de Estudios Peruanos.

SimilarWeb. (2019). Top Sites by country. https://www.similarweb.com/

Tafur, J. C. (2012). Pareja Presidencial S.A. Perú Económico, 35(9), 16-17.

Torrejón, P. (2013). Cubriendo la noticia: El Comercio: su representación del ciudadano indígena amazónico y la justificación del proyecto desarrollista [Tesis de maestría, Pontificia Universidad Católica del Perú]. Repositorio Institucional PUCP. http://hdl.handle.net/20.500.12404/5132

Varela, S. (1990). Fundamentos de morfología. Síntesis.

\section{Trayectoria académica de las autoras}

\section{Carolina Arrunátegui}

Es magíster en Lingüística (PUCP) y magíster en Estudios Culturales (PUCP). Actualmente, es estudiante de doctorado del programa Latin American, Iberian and Latino Cultures de la City University of New York (CUNY). Docente del Departamento de Humanidades de la PUCP y exconductora de Palabra del Perú, el espacio online de la Academia Peruana de la Lengua. Sus investigaciones están relacionadas con el análisis del discurso de los medios de comunicación desde una perspectiva social, crítica e interdisciplinaria. También ha estudiado el discurso de los libros de autoayuda amorosa y su relación con el capitalismo y la violencia de género en el contexto peruano.

\section{María Mercedes Palomino}

Es docente, periodista y magíster en Guion de Cine y TV por la Universidad Carlos III de Madrid (UC3M). Se desempeñó como periodista en la Agencia EFE, El Comercio y La República. Actualmente es docente universitaria de la Escuela de Comunicación Social de la Facultad de Letras y Ciencias Humanas de la Universidad Nacional Mayor de San Marcos y de la Universidad de San Martín de Porres. Sus investigaciones están relacionadas con los medios de comunicación, el periodismo y la cultura alimentaria. 